\title{
The LenSx Laser-A Review of Current Literature on its Use in Cataract Surgery
}

\author{
John Davidson, MD \\ Assistant Clinical Professor, Stein Eye Institute, UCLA School of Medicine, Los Angeles, CA, US
}

DOI: http://doi.org/10.17925/USOR.2016.09.01.16

\begin{abstract}
Laser cataract surgery (LCS) offers several surgical advantages over manual cataract surgery: the laser fragments the lens and creates corneal incisions and capsulotomies with a level of precision, control and reproducibility unachievable with manual techniques. The literature continues to expand and demonstrate many of the surgical benefits of LCS. There are important distinctions among the various femtosecond laser platforms that affect surgical technique. This review consolidates, organizes, and summarizes key published literature on the LenSx ${ }^{\circledR}$ Laser.
\end{abstract}

\section{Keywords}

Laser cataract surgery, LenSx ${ }^{\circledR}$ Laser, femtosecond laser technology

Disclosure: John Davidson, MD, is a paid consultant to Alcon.

Acknowledgements: Medical writing assistance was provided by Michelle Dalton and Bryan Bechtal for Touch Medical Media, funded by Alcon.

Open Access: This article is published under the Creative Commons Attribution Noncommercial License, which permits any noncommercial use, distribution, adaptation, and reproduction provided the original author(s) and source are given appropriate credit.

Received: October 9, 2015 Accepted: November 5, 2015 Citation: US Ophthalmic Review, 2016;9(1):16-20

Correspondence: John Davidson, MD, 3085 Loma Vista Road, Ventura, CA 93003, US. E: doctorjohn@johndavidsonmd.com

Support: Alcon sponsored the publication of this promotional piece. John Davidson, MD, received compensation from Alcon for his contributions to this publication. The content has been independently peer reviewed and verified by the US Ophthalmic Review publication process.

Several factors point to a potentially precipitous rise in the need for cataract surgery in the near future: population growth, increased awareness of and demand for excellent unaided vision, and the collateral benefits of improved vision after surgery. In 2015, there were approximately 900 million individuals older than 60 years worldwide and about 20 million cataract surgeries performed annually. ${ }^{1,2}$

These demographic factors exist against a backdrop of heightened patient expectations for refractive results from cataract surgery. Older individuals are leading increasingly active lifestyles and will require greater functional vision to meet their lifestyle demands. Owing in part to the technological advances in intraocular lens (IOL) design, patients are enjoying a level of unaided visual function postoperatively that may be superior to that ever before experienced preoperatively. Cataract surgery benefits patients beyond improved vision, including a decrease in falls and improvements in general physical, cognitive, and emotional wellbeing. ${ }^{3}$

In the US, femtosecond laser technology during cataract surgery is approved to create corneal incisions, perform the capsulotomy, and fragment the lens ${ }^{4,5}$ LCS has gained acceptance largely due to its perceived benefits compared to manual techniques: greater precision in the surgical steps and increased consistency. Published studies indicate LCS may be associated with greater accuracy of IOL power calculations, leading to greater predictability in refractive outcomes due to precise capsulotomy sizing and centering of the IOL., ${ }^{6,7}$

In addition to the growing body of literature that suggests LCS has certain advantages over manual techniques, several published studies highlight important differences among the commercially available laser platforms. This review discusses state-of-the-art LCS technologies, how they differ from manual techniques and between platforms, and how this growing sector of LCS will continue to meet the demands of cataract surgery.

\section{Laser Cataract Surgery-Defining the Principle}

There are five femtosecond laser platforms approved for use during cataract surgery: LenS ${ }^{\circledR}$ Laser (Alcon); Catalys* (AMO); LENSAR* (LENSAR Inc); Victus* (Bausch \& Lomb); and FEMTO LDV Z8* (Ziemer Ophthalmic Systems AG). Each platform incorporates anterior segment imaging, a patient interface (PI), and a femtosecond laser.

Key differentiating factors, particularly in the interface systems and fixed or variable aperture designs, have implications in surgical performance. Some platforms use a liquid optic interface while others use a soft hydrogel interface, which have differences in fixating the eye during the procedure. Also, some have a fixed bed with a fixed 
gantry relative to others that have a movable gantry with no fixed bed required. The LenS $x^{\circledR}$ Laser offers the benefit of a gurney rather than a fixed bed.

Identifying anatomic landmarks with anterior segment imaging is a critical component of LCS to ensure proper placement of the anterior

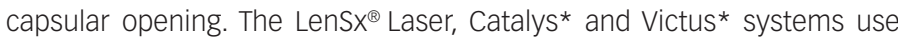
high-definition optical coherence tomography (HD OCT), while LENSAR* uses scheimpflug imaging technology.

\section{Laser Platform Interface}

The PI design is a critical differentiating factor in the various platforms. The laser platforms utilize either a contact or non-contact PI. The Catalys* and LENSAR* feature a non-contact liquid optical interface (LOI), the Victus* has a curved PI that is non-contact during the capsulotomy and fragmentation portions of the surgery but contact for corneal work, and the LenS $X^{\circledR}$ Laser uses a SoftFit'TM PI, a curved hydrogel contact lens interface (CCL) first introduced in 2012. SoftFit' ${ }^{\mathrm{TM}}$ PI uses a soft contact lens insert at the interface to minimize corneal compression. It may offer greater globe stability against pulsatile and ocular movements relative to noncontact interfaces, which may result in more consistent laser patterns and smoother morphology at the capsulotomy edge, compared to the Catalys* and Victus* systems. ${ }^{8}$ The fixation and stability of the eye with the SoftFit'TM PI contributes to the LenS $x^{\circledR}$ Laser's ability to do high-quality, complex corneal work, while also being able to accurately and effectively perform capsulotomies and lens fragmentation.

A LOI uses a liquid layer between the cornea and optical window of the laser to reduce corneal deformation. Coupling of the LOI to the eye is achieved using a suction ring outside the limbus. ${ }^{9}$ LOI use also requires the precise identification of the anterior corneal surface via sophisticated imaging techniques.

\section{Intraoperative Uses \\ Corneal Incisions}

Poor architecture of the main clear corneal incision (CCI) is a primary factor leading to surgically induced astigmatism (SIA), which can have consequences for post-surgical vision. ${ }^{10}$ The importance of such consequences may be magnified when implanting a multifocal or toric IOL. A cadaver eye study showed that cataract incisions made with a femtosecond laser were reproducible and stable, and were less likely to leak or become deformed during intraoperative maneuvers as compared to manual incisions. ${ }^{11}$ Mastropasqua et al. found laser CCls improved relative to manual $\mathrm{CCls}$, as measured by endothelial and epithelial gaping and misalignment. There was also a decrease in central endothelial cell loss. ${ }^{10} \mathrm{~A}$ study by Mayer showed significantly less endothelial cell loss with LenS $x^{\circledR}$ Laser cases compared to manual phacoemulsification. Overall, published data demonstrate improved incision quality and less endothelial cell loss during cataract surgeries when the LenS $x^{\circledR}$ Laser is used.

\section{Arcuate Corneal Incisions}

The degree of precision, control, and reproducibility of laser arcuate incisions cannot be matched with manual techniques. The arcuate incisions made by the LenS $x^{\circledR}$ Laser are customizable and can be created to an exact $80 \%$ depth.

\section{Capsulotomy}

IOL alignment with the visual axis is important to achieve the targeted refractive outcome. Holladay et al. found that an aspheric IOL that is decentered more than $0.4 \mathrm{~mm}$ and/or tilted $5^{\circ}$ off axis may yield unwanted visual consequences and less-than-desired performance.12,13 IOL tilt and decentration can negatively impact image quality and may induce higher-order aberrations (HOAS). ${ }^{13-15} \mathrm{~A}$ well-constructed capsulotomy is paramount in minimizing $\mathrm{IOL}$ decentration and tilt. Kranitz et al. noted that use of laser to perform the capsulotomy yielded significant improvements in vertical tilt, horizontal decentration, and total decentration. In the study, no patients in the laser group had vertical or horizontal tilt greater than $5^{\circ}$ or horizontal or vertical decentration greater than $0.4 \mathrm{~mm}$, whereas, the manual group had significantly higher rates of vertical tilt greater than $5^{\circ}$ $(p=0.008$ compared to laser) and significantly higher rates of horizontal decentration greater than $0.4 \mathrm{~mm}\left(\mathrm{p}=0.036\right.$ compared with laser). ${ }^{13}$

Photodisruption has been introduced as a mechanism to achieve a reproducible and predictably sized and centered capsulotomy. ${ }^{5,16}$ Porcine models have shown that laser capsulotomies are more precise and accurate, reproducible, and stronger compared with a manually cut capsulorhexis. ${ }^{17}$ A study by Kranitz et al. showed using the LenSX ${ }^{\circledR}$ Laser to perform the capsulotomy yielded significantly improved overlap of the capsulotomy and the IOL optic and enabled significantly greater circularity compared to manual techniques. ${ }^{16}$ In this study, horizontal decentration was $>0.4 \mathrm{~mm}$ at one week, one month, and one year after surgery in four, three, and five eyes, respectively, in the manual group, and none at all time points in the femtosecond laser group. ${ }^{16}$ The authors concluded IOL decentration was six times more likely in the manual versus laser group. ${ }^{16} \mathrm{~A}$ subsequent study by the same group demonstrated that IOL decentration correlated with changes in manifest refraction at one month and one year after surgery and that capsulotomies created with the LenS $X^{\circledR}$ Laser yielded a more stable refractive outcome. ${ }^{13}$

Bala et al. used electron microscopy to analyze the edge characteristics of capsulorhexes cut with manual techniques compared with capsulotomies performed with two generations of the LenS $x^{\circledR}$ Laser platform (LenS $x^{\circledR}$ Laser pre-SoftFit'M PI version 2.16 and LenS $x^{\circledR}$ Laser post-SoftFit ${ }^{T M}$ PI version 2.20), two generations of the Victus* platform (Victus I version 2.5 and Victus II version 2.7SP2), and Catalys* (version 2.15.13). The LenS $x^{\circledR}$ Laser postSoftFit ${ }^{\mathrm{M} M} \mathrm{PI}$ produced the fewest edge anomalies and the highest degree of reproducibility in performing the capsulotomy relative to Catalys* and Victus* ${ }^{*}$ Every platform, except the LenS $x^{\circledR}$ Laser post-SoftFit ${ }^{\top M}$ PI, generated statistically significantly less homogeneous capsulotomies as compared to manually created capsulotomies. ${ }^{8}$ Regression analysis found the homogeneity of capsulotomies performed with the LenS ${ }^{\circledR}$ Laser postSoftFit'M PI platform to be similar to those created manually. Furthermore, "several capsules generated by Catalys* and Victus* II showed tracks of pulses that appeared to have been misdirected inside the capsulotomy. These were not seen with the other laser platforms." ${ }^{\prime 8}$ The SoftFit' ${ }^{T M} \mathrm{PI}$ in the later generation of the LenS $x^{\circledR}$ Laser platform was thought to have caused less deformity and unimpeded laser transmission. ${ }^{8}$ The SoftFit ${ }^{\mathrm{TM}} \mathrm{PI}$, combined with the LenS $x^{\circledR}$ Laser device's proprietary variable numeric aperture, may help control for pulsatile eye movements as compared to a LOI. ${ }^{8}$

Roberts et al. reported on anterior capsule integrity of 3,355 cataract and refractive lens exchange cases performed in their institution, of which 
734 cases were operated using a curved, rigid interface and 2,621 with the LenSX ${ }^{\circledR}$ Laser SoftFit'TM $\mathrm{PI} .{ }^{18} \mathrm{~A}$ break in the capsule rim was identified in seven cases (0.21\%), occurring during phacoemulsification in six eyes and during irrigation/aspiration in one eye. Of note, five of the anterior capsule tears occurred in cases in which the curved, rigid interface was used and only two in which the SoftFit'T PI was used $(p=0.007)$. In studies, the LenSx Laser has demostrated free-floating capsulotomy rates in nearly $100 \%$ of cases.

\section{Lens Fragmentation}

During femtosecond laser lens fragmentation, a beam spot size of less than $6 \mu \mathrm{m}$ is used to generate plasma in the ocular tissue. ${ }^{19}$ This plasma, containing free electrons and ionized molecules, expands to cause a cavitation and formation of a bubble that expands and contracts to cause tissue separation, ${ }^{4,19}$ thereby reducing the amount of phacoemulsification energy delivered compared with manual techniques. Reduction of ultrasound energy has been associated with a reduced risk for lens capsule complications and corneal endothelial injury.,20-22 In a study on ex vivo porcine eyes, phacoemulsification with femtosecond laser phacofragmentation resulted in significant reductions in phacoemulsification power and time (51 and 43\%, respectively) compared with phacoemulsification alone ( $p \leq 0.001$ for both comparisons). ${ }^{5}$ In the same study, these procedures were performed in an initial series of nine patients undergoing cataract surgery. Femtosecond laser capsulotomies and phacofragmentation demonstrated similarly high levels of accuracy and effectiveness, with no operative complications. Cumulative dissipated energy and total phacoemulsification time were also lower with laser $\mathrm{CCl}$, which may reduce thermal injury at the incision site. ${ }^{10}$

Mayer et al. reported lower phacoemulsification time, fluid and energy among eyes operated with laser versus manual techniques, as well as significantly lower reduction in mean endothelial cell loss with laser (mean $114.90 \pm 87.90$ cells $/ \mathrm{mm}^{2}$ ) versus manual (mean $\left.173 \pm 111.16 \mathrm{cells} / \mathrm{mm}^{2}\right)^{23}$ A complete anterior capsulotomy was achieved in all eyes and there were no anterior capsule tears, posterior capsule ruptures, or phacoemulsification burns or bites in either group, the authors noted that previous studies have shown an association between lower phacoemulsification energy during cataract surgery and reduced postoperative corneal edema and endothelial cell loss, which may be important in patients with pre-existing corneal endothelial cell dysfunction, such as Fuchs' endothelial dystrophy.

My preferred routine pattern utilizes three chops that divide the lens nucleus into six segments, allowing efficient removal of the nucleus without leaving a posterior nuclear plate that can be difficult to safely remove. The LenS $x^{\circledR}$ Laser also has the ability to produce cylinder and grid/cube patterns that can be widely customized.

\section{Complicated Cases}

LCS has been studied in a number of complicated cataract scenarios, including intumescent white cataracts, traumatic cataracts, and eyes with concomitant phacomorphic glaucoma. ${ }^{22,24-26}$

One particular complicated patient type is the posterior pole cataract patient. In a retrospective chart review study, vasavada et al. described a lens fragmentation technique creating concentric circles before aspiration in eyes with posterior polar cataracts. ${ }^{27}$ Conventional hydrodelineation, referenced in that study, includes a risk for inadvertent cortical cleaving that does not present when using the femtosecond laser. Femtodelineation was shown to help avoid vertical pressure that may result from injecting liquid, thus mitigating the risk of posterior capsule blowout. Vasavada et al. reported posterior capsule rupture in two of 45 (4.4\%) eyes with posterior polar cataracts;, ${ }^{27}$ previous studies using manual hydrodelineation reported posterior capsule rupture as high as 26 to $36 \%$ in these types of cases. ${ }^{27-31}$

\section{Outcomes}

Compared to manual techniques, LCS provides improved lens position along the visual axis, which is attributed to the technology's ability to perform a consistently centered, repeatable, and predictable capsulotomy., ${ }^{5,13,16,17,32}$ LCS delivers improved predictability of refractive results. ${ }^{7,20,33}$

Filkorn etal. reported on 77 eyes treated with the LenS $x^{\circledR}$ Laser and 57 eyes treated with manual techniques: 41.6 and $68.8 \%$ of the LCS group were within $\pm 0.25 \mathrm{D}$ and \pm 0.50 D of targetrefraction postoperatively, respectively, compared to 28.1 and $46.9 \%$ in the manual group, respectively. ${ }^{7} \mathrm{~A}$ greater percentage of patients were \pm 0.50 SD in the LenS $x^{\circledR}$ Laser group. Further, the mean absolute error (MAE), a measure of predictability, was lower in the LenS $x^{\circledR}$ Laser group.

The ability to create an accurate and reproducible capsulotomy may significantly impact the visual outcome. Kranitz et al. reported significantly worse corrected distance visual acuity at one month in eyes operated with manual versus laser techniques, which they attributed to the possible inducement of higher-order aberrations secondary to lens tilt in the manual group that could not be corrected with spectacles. ${ }^{13}$ The authors noted that IOL decentration correlated with changes in manifest refraction at one month and one year after surgery and that capsulotomies created with the LenS ${ }^{\circledR}$ Laser yielded a more stable refractive outcome.

\section{Safety Data}

compared to manual techniques, using the femtosecond laser for portions of the surgical procedure may help reduce the risk of intraoperative complications. I have found the OCT imaging useful in revealing lens thickness. When handing the phacoemulsification handpiece, the surgical technician reminds me whether the lens is thicker or thinner than normal, which allows me to better judge how deep I can safely work on the nucleus for chopping. Numerous studies have shown reduced endothelial cell loss and reduced postoperative inflammation with LCS. ${ }^{20,34,35}$

Roberts et al. reported on 3,355 cases operated at their facility using LenS $x^{\circledR}$ Laser (734 with a rigid interface and 2,621 with the SoftFit PI). ${ }^{18}$ The authors reported an overall complication rate of $0.21 \%$, which compared favorably to the $0.31 \%$ complication rate noted in their earlier study. It should also be noted that in four of these cases, IOL implantation was still achievable: and two in which sulcus IOL implantation was safely performed in eyes in which the tear extended to the posterior capsule; and two in which in-the-bag implantation was successfully performed in eyes in which the tear extended to the equator without posterior capsule involvement or vitreous loss. The rates of anterior capsule tear, posterior 
capsule tear (with or without vitreous loss), and posterior lens dislocation were all significantly lower after LenS $x^{\circledR}$ Laser LCS than rates reported for similar events among recipients of manual surgery. ${ }^{6}$

After implementing the SoftFit'TM PI, anterior capsule tear was reduced to two of 2,621 cases (0.07\%). ${ }^{18}$ Abell et al. reported a 1.9\% anterior capsule tear rate when using the Catalys* ${ }^{*}$ which was higher than manual. ${ }^{36}$

Published reports also indicate LCS use contributes to a reduction in complications during training cases by both residents and fellows. ${ }^{37}$ Reductions in total ultrasound, phacoemulsification, torsional, and aspiration times compared with manual techniques may be particularly important in this setting, as training surgeon cases have historically been associated with high complication rates. ${ }^{37}$ In published studies, risk of inducing an anterior capsule tear has been most closely associated with lack of surgeon experience, evidenced by lower rates among more experienced surgeons. ${ }^{38}$

\section{Postoperative Inflammation}

Phacoemulsification energy, a potential source of postoperative inflammation that can manifest as iritis, corneal edema, increased cell and flare, and hyperalgesia or pain, is reduced with $\operatorname{LCS}^{5,20,21,34,39}$ It has been suggested that LCS may be advantageous as it may help mitigate the physiologic changes (including anterior segment inflammation as measured via laser flare photometer). ${ }^{34}$

\section{Surgical Efficiency}

The LenS $x^{\circledR}$ Laser typically performs a surgical time under two minutes (direct suction time). Other systems may take more total suction time, depending on both platform and programmed degree of lens softening. 19,40 Of the LCS platforms, only LenSX ${ }^{\circledR}$ Laser offers a single-piece PI without the need for water. The interface gently makes contact rather than first fitting a suction ring directly onto the patient's eye followed by docking the patient up to the laser objective head. ${ }^{40}$

Some platforms possess a fixed bed, which can help stabilize the head during image capture and treatment, but brings with it the necessity of moving a patient to another bed for the remainder of the surgery. ${ }^{19}$

\section{Future Directions}

The growing body of evidence on the use of LCS is consistently showing certain advantages over manual techniques, while noting differences among the platforms. ${ }^{6,7,13,18,19,32,36,41}$ Reported complication rates are low and may be platform-related rather than category-dependent. Innovation in the surgical platform technology is ongoing. Generational improvements in software and hardware have already produced additional laser patterns, auto pre-positioning, speed and improvements in the PI, the latter of which confers greater control of the globe and more precise laser delivery. I continue to believe this technology delivers greatly now and even has the potential to deliver more moving forward. I am equally certain the growing body of literature confirms this belief.
1. United Nations Department of Economic and Social Affairs Population Division, World Population Ageing 2013. Available at: http://www.un.org/en/development/desa/population/ publications/pdf/ageing/WorldPopulationAgeing2013.pdf (accessed September 30, 2015)

2. Lindstrom R, Thoughts on Cataract Surgery: 2015, Review of Ophthalmology, 2015, Available at: http://www. reviewofophthalmology.com/content/t/cataract/c/53422 (accessed October 1, 2015).

3. Morris D, Fraser SG, Gray C, Cataract surgery and quality of life implications, Clin Interv Aging, 2007:2:105-8.

4. Lawless M, Bala C, Femtosecond laser-assisted cataract surgery, US Ophthalmic Rev, 2014;7:82-8.

5. Nagy Z, Takacs A, Filkorn T, Sarayba M, Initial clinical evaluation of an intraocular femtosecond laser in cataract surgery, I Refract Surg, 2009;25:1053-60.

6. Roberts TV, Lawless M, Bali SJ, et al., Surgical outcomes and safety of femtosecond laser cataract surgery: a prospective study of 1500 consecutive cases, Ophthalmology, 2013;120:227-33.

7. Filkorn T, Kovacs I, Takacs A, et al., Comparison of IOL power calculation and refractive outcome after laser refractive cataract surgery with a femtosecond laser versus conventional phacoemulsification, J Refract Surg, 2012;28:540-4.

8. Bala C, Xia Y, Meades K, Electron microscopy of laser capsulotomy edge: Interplatform comparison, I Cataract Refract Surg, 2014:40:1382-9.

9. Talamo $\mathrm{JH}$, Gooding P, Angeley $\mathrm{D}$, et al., Optical patient interface in femtosecond laser-assisted cataract surgery: contact corneal applanation versus liquid immersion, J Cataract Refract Surg, 2013;39:501-10.

10. Mastropasqua L, Toto L, Mastropasqua A, et al., Femtosecond Laser Versus Manual Clear Corneal Incision in Cataract Surgery, I Refract Surg, 2014;30:27-33

11. Masket S, Sarayba M, Ignacio T, Fram N, Femtosecond laser-assisted cataract incisions: architectural stability and reproducibility, J Cataract Refract Surg, 2010;36:1048-9.

12. Holladay JT, Piers PA, Koranyi G, et al., A new intraocular lens design to reduce spherical aberration of pseudophakic eyes, J Refract Surg, 2002;18:683-91.

13. Kranitz K, Mihaltz K, Sandor GL, et al., Intraocular lens tilt and decentration measured by Scheimpflug camera following manual or femtosecond laser-created continuous circular capsulotomy, I Refract Surg, 2012:28:259-63.

14. Auran JD, Koester CJ, Donn $A$, In vivo measurement of posterior chamber intraocular lens decentration and tilt, Arch Ophthalmol, 1990;108:75-9.

15. Baumeister M, Buhren J, Kohnen T, Tilt and decentration of spherical and aspheric intraocular lenses: effect on higher-order aberrations, I Cataract Refract Surg, 2009;35:1006-12

16. Kranitz K, Takacs A, Mihaltz K, et al., Femtosecond laser capsulotomy and manual continuous curvilinear capsulorrhexis parameters and their effects on intraocular lens centration, Refract Surg, 2011;27:558-63.

17. Friedman NJ, Palanker DV, Schuele G, et al., Femtosecond laser capsulotomy, I Cataract Refract Surg, 2011;37:1189-98.

18. Roberts TV, Lawless M, Sutton G, Hodge C, Anterior capsule integrity after femtosecond laser-assisted cataract surgery J Cataract Refract Surg, 2015:41:1109-10.

19. Donaldson KE, Braga-Mele R, Cabot F, et al., Femtosecond laser-assisted cataract surgery, J Cataract Refract Surg, 2013:39:1753-63.

20. Abell RG, Kerr NM, Vote BJ, Toward zero effective phacoemulsification time using femtosecond laser pretreatment, Ophthalmology, 2013;120:942-8.

21. Conrad-Hengerer I, Hengerer FH, Schultz T, Dick HB, Effect of femtosecond laser fragmentation on effective phacoemulsification time in cataract surgery, J Refract Surg, 2012:28:879-83.

22. Conrad-Hengerer I, Hengerer FH, Schultz T, Dick HB, Femtosecond laser-assisted cataract surgery in eyes with a small pupil, J Cataract Refract Surg, 2013;39:1314-20.

23. Mayer WJ, Klaproth OK, Hengerer FH, Kohnen T, Impact of crystalline lens opacification on effective phacoemulsification time in femtosecond laser-assisted cataract surgery, $A m$ J Ophthalmol, 2014:157:426-32 e1.

24. Conrad-Hengerer I, Hengerer $\mathrm{FH}$, Joachim SC, et al , Femtosecond laser-assisted cataract surgery in intumescent white cataracts, I Cataract Refract Surg, 2014:40:44-50.

25. Dick HB, Schultz T, Femtosecond laser-assisted cataract surgery in infants, J Cataract Refract Surg, 2013;39:665-8.

26. Nagy ZZ, Kranitz K, Takacs A, et al., Intraocular femtosecond laser use in traumatic cataracts following penetrating and blunt trauma, J Refract Surg, 2012;28:151-3.
27. Vasavada AR, Vasavada V, Vasavada $S$, et al., Femtodelineation to enhance safety in posterior polar cataracts, J Cataract Refract Surg, 2015;41:702-7.

28. Hayashi K, Hayashi H, Nakao F, Hayashi F, Outcomes of surgery for posterior polar cataract, I Cataract Refract Surg, 2003;29:45-9

29. Osher RH, Yu BC, Koch DD, Posterior polar cataracts: a predisposition to intraoperative posterior capsular rupture $\_$ Cataract Refract Surg, 1990:16:157-62.

30. Vasavada A, Singh R, Phacoemulsification in eyes with posterior polar cataract, I Cataract Refract Surg, 1999;25:238-45.

31. Vasavada AR, Raj SM, Inside-out delineation, I Cataract Refract Surg, 2004;30:1167-9.

32. Nagy ZZ, Kranitz K, Takacs Al, et al., Comparison of intraocula lens decentration parameters after femtosecond and manual capsulotomies, J Refract Surg, 2011;27:564-9.

33. Lawless M, Bali SJ, Hodge C, et al., Outcomes of femtosecond laser cataract surgery with a diffractive multifocal intraocular lens, I Refract Surg 2012:28:859-64.

34. Abell RG, Allen PL, Vote BJ, Anterior chamber flare after femtosecond laser-assisted cataract surgery, I Cataract Refract Surg, 2013;39:1321-6.

35. Abell RG, Kerr NM, Vote BJ, Femtosecond laser-assisted cataract surgery compared with conventional cataract surgery, Clin Experiment Ophthalmol, 2013;41:455-62.

36. Abell RG, Davies PE, Phelan D, et al., Anterior capsulotomy integrity after femtosecond laser-assisted cataract surgery Ophthalmology, 2014:121:17-24.

37. Hou JH, Prickett AL, Cortina MS, et al., Safety of femtosecond laser-assisted cataract surgery performed by surgeons in training, J Refract Surg, 2015;31:69-70

38. Day AC, Gartry DS, Maurino V, et al., Efficacy of anterior capsulotomy creation in femtosecond laser-assisted cataract surgery, I Cataract Refract Surg, 2014:40:2031-4.

39. Rajpal RK, Roel L, Siou-Mermet R, Erb T, Efficacy and safety of loteprednol etabonate $0.5 \%$ gel in the treatment of ocular inflammation and pain after cataract surgery, J Cataract Refract Surg, 2013;39:158-67.

40. Yeoh $R$, Practical differences between 3 femtosecond phaco laser platforms, I Cataract Refract Surg, 2014;40:510.

41. Bala C, Lawless M, Davidson J, Cataract Refractive Surgery Myth Busters, Ophthalmol Times, Cleveland, Ohio: Advanstar, 2014. 